\title{
Indicador de Vulnerabilidade para Gestão da Conservação de Edifícios de Valor Cultural
}

\author{
Vulnerability Indicator for the Management of the Conservation of \\ Buildings of Cultural Value
}

\author{
Indicador de vulnerabilidad para la gestión de conservación de \\ edificios de valor cultural
}

\author{
MEIRA, Ingrid Orlandi ${ }^{1}$ \\ ZANONI, Vanda Alice Garcia ${ }^{2}$ \\ 3Programa de Pós-Graduação - PPG-FAU, Universidade de Brasília, Brasília, Brasil. om.ingrid@gmail.com \\ ORCID: 0000-0002-7558-961X \\ 3Programa de Pós-Graduação - PPG-FAU, Universidade de Brasília, Brasília, Brasil. vandazanoni@unb.br \\ ORCID: 0000-0003-2629-4214
}

Recebido em 08/02/2020 Aceito em 15/05/2020

\begin{abstract}
Resumo
Compreender a complexidade no acondicionamento de acervo museológico aliado às exigências físicas e funcionais do edifício é uma das dificuldades enfrentadas pelos gestores de museus. Este artigo apresenta um método de gestão de risco baseado em um Indicador de Vulnerabilidade (IVU) que representa de forma integrada os diversos fatores e valores que afetam a conservação do edifício de valor cultural e seu acervo museológico. A formulação do IVU foi baseada no Método Fatorial da ISO 15686-8 que considera sete variáveis: A-qualidade material, B-projeto arquitetônico, C-qualidade de execução da obra, D-características do ambiente interno, E-características do ambiente externo, Fcondições de uso e G-nível de manutenção. Associado aos fatores que afetam a funcionalidade e o estado de conservação da edificação e seu acervo, foi desenvolvido o Índice de Valor Cultural (IVC) para valorar os aspectos culturais, relacionados à excepcionalidade, à imaterialidade e aos atributos que conferem significância ao patrimônio. Foi feita uma aplicação experimental do Método IVU no Museu Nacional do Conjunto Cultural da República, in Brasília-DF. Os resultados mostram que o método proposto é uma ferramenta capaz de avaliar individualmente um museu, mas também um conjunto de museus, identificando o potencial de risco inerente e a vulnerabilidade do edifício e seus acervos. Visualmente, o gráfico síntese da ferramenta foi capaz de representar os resultados nas distintas situações para a gestão de riscos de um conjunto de edifícios, para além de uma unidade isolada, de modo que o gestor possa avaliar de forma mais integrada os problemas existentes e monitorá-los ao longo do tempo.
\end{abstract}

Palavras-Chave: Gestão da conservação; Indicadores; Vulnerabilidade; Edifícios de valor cultural; Museus; Arquitetura Moderna. 
Abstract

Understanding the complexity of stowing museological collections combined with the physical and functional requirements of the building is one of the difficulties faced by museum managers. This article presents a risk management method based on a Vulnerability Indicator (IVU) that represents in an integrated way the various factors and values that affect the conservation of the cultural value building and its museum collections. The formulation of the IVU was based on the Factorial Method of ISO 15686-8, which considers seven variables: A-material quality, B-architectural design, C-quality of the work execution, $D$-characteristics of the internal environment, E-characteristics of the external environment, F-conditions of use and G-level of maintenance. Associated with the factors that affect the functionality and the state of conservation of the building and its collection, the Cultural Value Index (CVI) was developed to value cultural aspects, related to exceptionality, immateriality and the attributes that give significance to the heritage. An experimental application of the IVU Method was made at the National Museum of the Cultural Complex of the Republic, in Brasilia-DF. The results show that the proposed method is a tool capable of evaluating a single museum, but also a set of museums, identifying the inherent potential risk and the vulnerability of the building and its collections. Visually, the summary graphic of the tool was able to display the results in different situations for the management of risks of a set of buildings, in addition to an isolated unit, in a way that the manager can assess in a more integrated form the existing problems and monitoring them over time.

Key-Words: Conservation management; Indicators; Vulnerability; Buildings of cultural value; Museums; Modern architecture.

\section{Resumen}

Comprender la complejidad en el acondicionamiento de acervo museológico combinado a los requisitos físicos y funcionales del edificio es una de las dificultades que enfrentan los gerentes de museos. Este artículo presenta un método de gestión de riesgos basado en un Indicador de Vulnerabilidad (UIV) que representa de manera integrada los diversos factores y valores que afectan la conservación del valor cultural y su acervo museológico. La formulación de la IVU se basó en el Método Factorial del ISO 15686-8 que considera siete variables: A-cualidad del material, B-diseño arquitectónico, C-cualidad de ejecución del trabajo, $D$-características del ambiente interno, E-características del ambiente externo , $F$ condiciones de uso y G-nivel de mantenimiento. Asociado con los factores que afectan la funcionalidad y el estado de conservación del edificio y su acervo, el Índice de Valor Cultural (CVI) se desarrolló para valorar los aspectos culturales, relacionados con la excepcionalidad, la inmaterialidad y los atributos que dan importancia al patrimonio. Se realizó una aplicación experimental del Método IVU en el Museo Nacional del Conjunto Cultural de la República, en Brasilia-DF. Los resultados muestran que el método propuesto es una herramienta capaz de evaluar individualmente un museo, pero también un conjunto de museos, identificando el potencial de riesgo inherente y la vulnerabilidad del edificio y sus acervos. Visualmente, el gráfico de síntesis de la herramienta fue capaz de representar los resultados en diferentes situaciones para la gestión de riesgos de un conjunto de edificios, además de una unidad aislada, para que el administrador pueda evaluar los problemas existentes de una manera más integrada y los monitorear a lo largo del tiempo.

Palabras clave: Gestión de la conservación; Indicadores; Vulnerabilidad; Edificios de valor cultural; Museos; Arquitectura moderna 


\section{Introdução}

A Organização das Nações Unidas para a Educação, a Ciência e a Cultura - UNESCO considera que um sistema de gestão para o patrimônio cultural contribui para a proteção dos seus valores, sejam eles de um bem ou conjunto de bens. A gestão deve agir de forma responsiva, tendo em vista que os valores do patrimônio e as tomadas de decisões não são estáticos, eles mudam ao longo do tempo, de acordo com os grupos sociais envolvidos, a cultura, as mudanças ambientais, entre outros (UNESCO, 2016).

No campo da Gestão de Risco, a boa gestão se "inicia com a identificação de quais são os riscos existentes, uma vez que somente riscos conhecidos podem ser adequadamente tratados" (POLITO, 2015; p. 201). Com o conhecimento de cada um dos potenciais riscos é possível que o gestor faça escolhas. Essas escolhas podem estar relacionadas à urgência de solucionar um problema, à verba disponível, à necessidade no trabalho interno, à necessidade dos usuários, entre outras. A UNESCO (2016) apresenta uma pesquisa que aponta os problemas ligados à gestão como uma forte ameaça ao Patrimônio Mundial, com percentuais próximos às ameaças provenientes das ações para o desenvolvimento e infraestrutura urbanos.

Entre os anos de 2018 e 2019, os incêndios de grandes proporções que devastaram o Museu Nacional da Quinta na Boa Vista, no Rio de Janeiro, e a Catedral de Notre-Dame de Paris afetaram profundamente esses bens de valor cultural pela perda significativa de seu acervo consumido pelas chamas. Esses sinistros, entre outros ocorridos nas últimas décadas, alertam para a gestão de riscos dos espaços culturais e de significância patrimonial.

Este artigo apresenta um método de gestão de risco baseado em um Indicador de Vulnerabilidade (IVU) que representa de forma integrada os diversos fatores e valores que afetam a conservação do edifício de valor cultural e seu acervo museológico. Em especial, a opção pelas instituições museológicas para o desenvolvimento desta pesquisa se deu pela relação de interdependência entre o acervo e o edifício que o abriga. Tendo sido construídos para se tornarem museus ou não, é esperado que essas edificações possam suprir as necessidades de guarda e proteção de seus acervos.

Quando se trata de edifícios de valor cultural, além de atender às necessidades do acervo, é preciso manter os valores que transmitem enquanto bens culturais, ancorados na materialidade e na integridade do edifício (ICOMOS, 1994; 2013). Um dos desafios do método de gestão proposto é pensar tanto o edifício como o acervo de forma integrada.

Nos museus localizados em edifícios de valor cultural, a conservação do edifício, seus valores, sua funcionalidade e a conservação de seu acervo museológico estão interligados. No entanto, há uma escassez de metodologias integradas que tratam desses aspectos, especialmente em espaços museológicos, objetos de estudo dessa pesquisa. $O$ interesse por esse recorte de pesquisa se consolida, principalmente, quando os fatos revelam que muitos gestores de museus não são profissionais com formação especializada e ligada ao campo da preservação e, ainda assim, lidam com a etapa de levantamento preliminar das condições de vulnerabilidade dos espaços que gerem.

É comum que exemplares do patrimônio edificado abriguem instituições culturais. Muitas instituições museológicas são exemplos disso no Brasil e no mundo. Para tanto, os edifícios, grande parte das vezes, necessitam de transformações para melhor se adaptarem à vida cotidiana da contemporaneidade e, ao mesmo tempo, às necessidades de um acervo museológico. Por serem exemplares de um passado recente, não são tão evidentes os limites acerca das intervenções que podem prejudicar sua integridade e autenticidade (ICOMOS, 2013). O Indicador de Vulnerabilidade (Método IVU) aqui apresentado pode contribuir enquanto ferramenta para identificar o potencial de risco inerente ao estoque de edifícios analisados, de forma que seja possível hierarquizar necessidades e planejar ações de preservação do patrimônio cultural, considerando tanto os seus 
valores culturais como a sua materialidade.

\section{Preservação e Gestão de Edifícios de Valor Cultural}

Os valores atribuídos ao bem imóvel podem ser influenciados por diversos fatores que tornam os edifícios mais ou menos vulneráveis do ponto de vista da conservação. Fatores como a qualidade do ambiente interno da edificação, as condições de uso e exposição, entre outros, quando inadequados, podem ser consideradas riscos para o patrimônio edificado.

Segundo Souza et al. (2018), a escolha inadequada de materiais pode comprometer a funcionalidade de todo um sistema. Para determinar a qualidade dos materiais é necessário utilizar os dados de ensaios de caracterização e propriedades, adequados às necessidades de conservação do acervo e do edifício. Quando o momento de construção é passado, nem sempre é possível ter acesso aos dados dos materiais utilizados. Neste caso, podendo ser feitos ensaios não destrutivos, in situ (MESQUITA, 2019).

A norma de desempenho de edificações NBR 15575-1 estabelece que a adequação ao uso de um sistema construtivo destinado a cumprir uma função deve ocorrer independentemente da solução técnica adotada, e alerta que é papel do fornecedor de produtos caracterizar seu desempenho, isto é, o comportamento nas condições de uso e exposição. Ainda, sustenta que a escolha dos componentes do edifício deverá ser feita não somente pela aparência estética, mas pela resistência, formato, durabilidade e compatibilização com as demais partes do sistema (ABNT, 2013).

Durante a fase de projeto é possível prever e prevenir anomalias no edifício. Muitas anomalias que são encontradas durante as inspeções prediais são resultantes de erros ou deficiências de projeto, que poderiam ser evitadas (EMÍDIO et al., 2014). Entre as soluções que afetam a qualidade do projeto estrutural estão o detalhamento das armaduras, o uso de formas arquitetônicas e estruturais, a espessuras do cobrimento ou revestimentos protetores em regiões sob condições de exposição ambiental muito agressivas e projeto de drenagem eficiente (HELENE, 1997; ABNT, 2014). A qualidade de execução da obra, que se revela no nível de habilidade e controle no canteiro de obras durante a construção, pode ser favorecida quando as recomendações do fabricante e as orientações projetuais são seguidas. Esse fator pode compreender desde o armazenamento adequado dos materiais até a forma de instalação, por exemplo.

O museu, por definição, deve ser uma instituição que contribui para a preservação do valor cultural do edifício museu (ICOM, 2015). É a coleção que irá direcionar as condições higrotérmicas do ambiente interno (FERREIRA, 2015). A temperatura e a umidade são os principais agentes de degradação quando se trata de acervos museológicos. Esses agentes afetam, mais ou menos, os objetos do acervo, que sofrem danos e respondem de diferentes maneiras dependendo de cada tipo de material que o compõe. Além deles, outras condições do ambiente interno são importantes para a análise das condições de exposição do acervo, como a presença da luz e dos agentes biológicos (como os insetos xilófagos, traças e baratas; os fungos e as bactérias; entre outros) (DRUMOND, 2006).

As características do ambiente externo têm influência sobre o edifício e também sobre o acervo museológico. Segundo Souza et al. (2018), o envelope do edifício é o mais propenso à degradação em consequência dos agentes ambientais, como a poluição do ar, a distância do mar, a radiação solar, além da chuva dirigida e do efeito do vento. Silva, Brito e Gaspar (2016) pontuam ainda outras questões a serem analisadas, como topografia local, vegetação, construções adjacentes, fontes de umidade, efeitos da insolação e sombreamentos na superfície das fachadas.

As condições de uso são determinadas pela influência dos usuários sobre os sistemas e componentes do edifício (EMÍDIO et al., 2014). Segundo Jardim et al. (2019), os danos causados intencionalmente ao edifício, como vandalismos e pichações, assim como assaltos e acidentes, são considerados como 
riscos provenientes das condições de uso.

A NBR 5674 (ABNT, 2012) define o sistema de manutenção como o "conjunto de procedimentos organizados para gerenciar os serviços de manutenção" e, por sua vez, o serviço de manutenção é a "intervenção realizada na edificação e seus sistemas, elementos ou componentes constituintes" (ABNT, 2012; p. 3), assim classificados:

\begin{abstract}
a) manutenção rotineira: caracterizada por um fluxo contínuo de serviços, padronizados e cíclicos, citando-se, por exemplo, limpeza geral e lavagem de áreas comuns.

b) manutenção corretiva: caracterizada por serviços que demandam ação ou intervenção imediata a fim de permitir a continuidade do uso dos sistemas, elementos e componentes das edificações, ou evitar grandes riscos ou prejuízos pessoais ou patrimoniais aos seus usuários ou proprietários.

c) manutenção preventiva: caracterizada por serviços cuja realização seja programada com antecedência, priorizando as solicitações dos usuários, estimativas da durabilidade esperada dos sistemas, elementos ou componentes das edificações em uso, gravidade e urgência, e relatórios de verificações periódicas sobre o seu estado de degradação. (ABNT NBR 5674: 2012; p. 3)
\end{abstract}

Para além das questões técnicas que relacionam essas duas esferas, o edifício e o acervo museológico, Gabriele (2012) enxerga o edifício também como um acervo que pode servir de instrumento social sendo que "seu conteúdo histórico, técnico, estético e social podem ser comunicados com vistas à inclusão e desenvolvimento social" (GABRIELE, 2012, p.125), levando a crer na necessidade de preservá-lo.

Durante um longo período, os valores atribuídos ao edifício, em especial para atestar sua autenticidade, estavam mais ligados às questões materiais apenas. A UNESCO buscava nos projetos, materiais, técnicas construtivas e entorno a verificação do edifício como um bem de valor cultural. Em 1994, com a Conferência de Nara, foram reconhecidas as diversidades entre os bens materiais, verificando a necessidade de analisar cada bem conforme seu espaço e tempo. Além disso, foram revistos os critérios para verificação da autenticidade dos mesmos, incluindo critérios de natureza não material e dinâmica: forma e projeto, materiais e substância, uso e função, tradições e técnicas, localização e espaço, espírito e sentimento, além de outros fatores internos e externos (LIRA, 2009).

Segundo a Conferência de Nara, o conhecimento e a compreensão dos valores estão condicionados à veracidade e credibilidade das fontes de informação e são requisitos básicos para a avaliação de todos os aspectos da autenticidade (ICOMOS, 1994). Tanto os valores atribuídos, quanto a credibilidade dada a cada uma das fontes de informação variam entre culturas e até mesmo dentro de uma mesma cultura, sendo, portanto, variáveis os julgamentos de valor.

Os conceitos e parâmetros aqui destacados estão interligados e possuem relações de interdependência. Essas relações ocorrem de muitas maneiras, sendo necessário um levantamento cuidadoso de evidências para a categorização e estabelecimento de critérios de análise de cada fator e valor inerentes às conservação e gestão das edificações e de seu acervo.

\title{
3. Metodologia Proposta
}

\subsection{Referencial Teórico: Método Fatorial}

A metodologia proposta neste trabalho, para a obtenção de um Indicador de Vulnerabilidade, tem como base referencial o Método Fatorial apresentado pela ISO 15686-8:2008 - Reference service life and service-life estimation. O Método Fatorial tem como objetivo estimar a vida útil de componentes ou sistemas em determinadas condições de exposição, e é expresso por uma fórmula matemática baseada em 7 fatores variáveis que afetam a vida útil de referência do componente a ser analisado. Os fatores variáveis da ISO 15686-8:2008 são: nível de qualidade dos componentes (Fator A), nível de 
qualidade de projeto (Fator B), nível de qualidade de execução (Fator C), características do ambiente interno (Fator D), características do ambiente externo (Fator E), condições de uso (Fator F) e nível de manutenção (Fator

$E S L=R S L \times A \times B \times C \times D \times E \times F \times G$ G). A Equação 1 mostra o modelo teórico

apresentado na ISO 15686-8:2008.

Onde:

ESL $=$ Vida Útil Estimada

RSL = Vida Útil de Referência

$\mathbf{A}=$ Nível de qualidade do material ou componente

B = Nível de qualidade de projeto

C = Nível de qualidade de execução

D = Características do ambiente interno

$\mathbf{E}=$ Características do ambiente externo

$\mathbf{F}=$ Condições de uso

$\mathbf{G}=$ Nível de manutenção

\subsection{Proposta de um Indicador de Vulnerabilidade (IVU)}

Nesta pesquisa, o Método Fatorial apresentado na ISO 15686-8:2008 foi adaptado para a obtenção de um Indicador de Vulnerabilidade (IVU). As métricas ESL (vida útil estimada) e RSL (vida útil de referência) foram substituídas pelos ICOabs (Índice de Conservação Absoluto) e IVC (Índice de Valor Cultural), respectivamente. O modelo matemático do método proposto nesta pesquisa é expresso na Equação 2.

\section{ICOabs = IVC x A x B x C x D x E x F x G}

Onde:

ICOabs = Índice de Conservação Absoluto

IVC = Índice de Valor Cultural

Fator $\mathbf{A}=$ Nível de qualidade dos sistemas construtivos e suas partes: materiais, componentes, elementos

Fator $\mathbf{B}=$ Nível de qualidade do projeto arquitetônico

Fator $\mathbf{C}=$ Nível de qualidade de execução da obra

Fator $\mathbf{D}=$ Características do ambiente interno

Fator $\mathbf{E}=$ Características do ambiente externo

Fator $\mathbf{F}=$ Condições de uso

Fator $\mathbf{G}=$ Nível de manutenção

Para a obtenção dos índices propostos foi criado um conjunto de critérios balizadores dos procedimentos para determinação e quantificação das incógnitas envolvidas na Equação 2.

\subsection{Critérios para obtenção dos Fatores}

Para os fatores A, B, C, D, E, F, G, são atribuídos os valores numéricos 0,$6 ; 0,8 ; 1,0$ e 1,2, conforme os critérios especificados para a valoração de cada um deles, baseado nas evidências encontradas nos procedimentos de avaliação do bem cultural.

Para a quantificação de cada um dos fatores deve ser realizado um levantamento de dados de campo e documental. Por meio da inspeção visual e análise de dados documentais disponíveis, segundo cada objeto de investigação, são apresentadas as evidências (manifestações patológicas, falhas ou danos) e as análises das possíveis causas e efeitos. Após identificar e caracterizar a situação encontrada, os dados obtidos e as análises realizadas devem permitir a avaliação do fator, de acordo com as condições encontradas. Nesse sentido, a caracterização do estado de conservação do bem patrimonial é essencial. 
Considerando que não existe um banco de dados sistematizados sobre o estado de conservação ao longo da vida útil dos edifícios culturais destinados a museu, de forma a permitir abordagens probabilísticas, nesta proposta adotou-se o método determinístico onde são atribuídos os valores numéricos $(0,6 ; 0,8 ; 1,0$ e 1,2$)$ para cada um dos fatores, proporcionais às evidências encontradas. $A$ atribuição dos valores numéricos é feita com base nos critérios (ver Quadros 1 a 9) que fundamentam a avaliação.

\section{4 Índice de Valor Cultural (IVC)}

Os aspectos e critérios que servem de parâmetro para determinar o IVC - Índice de Valor Cultural foram baseados nos valores definidos por Riegl (2014), nos indicadores apresentados por Lira (2009) para autenticidade, e nos critérios para Valor Universal Excepcional, integridade e autenticidade determinados pela UNESCO (2018). Na seleção dos critérios, foram considerados tanto aqueles relacionados à materialidade quanto à imaterialidade que compõem a valoração cultural.

Para a análise de cada critério devem ser levantados os dados históricos do edifício, informações sobre seu acervo museológico e caracterização do edifício objeto de análise. O Quadro 1 indica os aspectos e critérios a serem adotados para a valoração do IVC.

Quadro 1: Aspectos e critérios para avaliação do valor cultural em museus modernistas

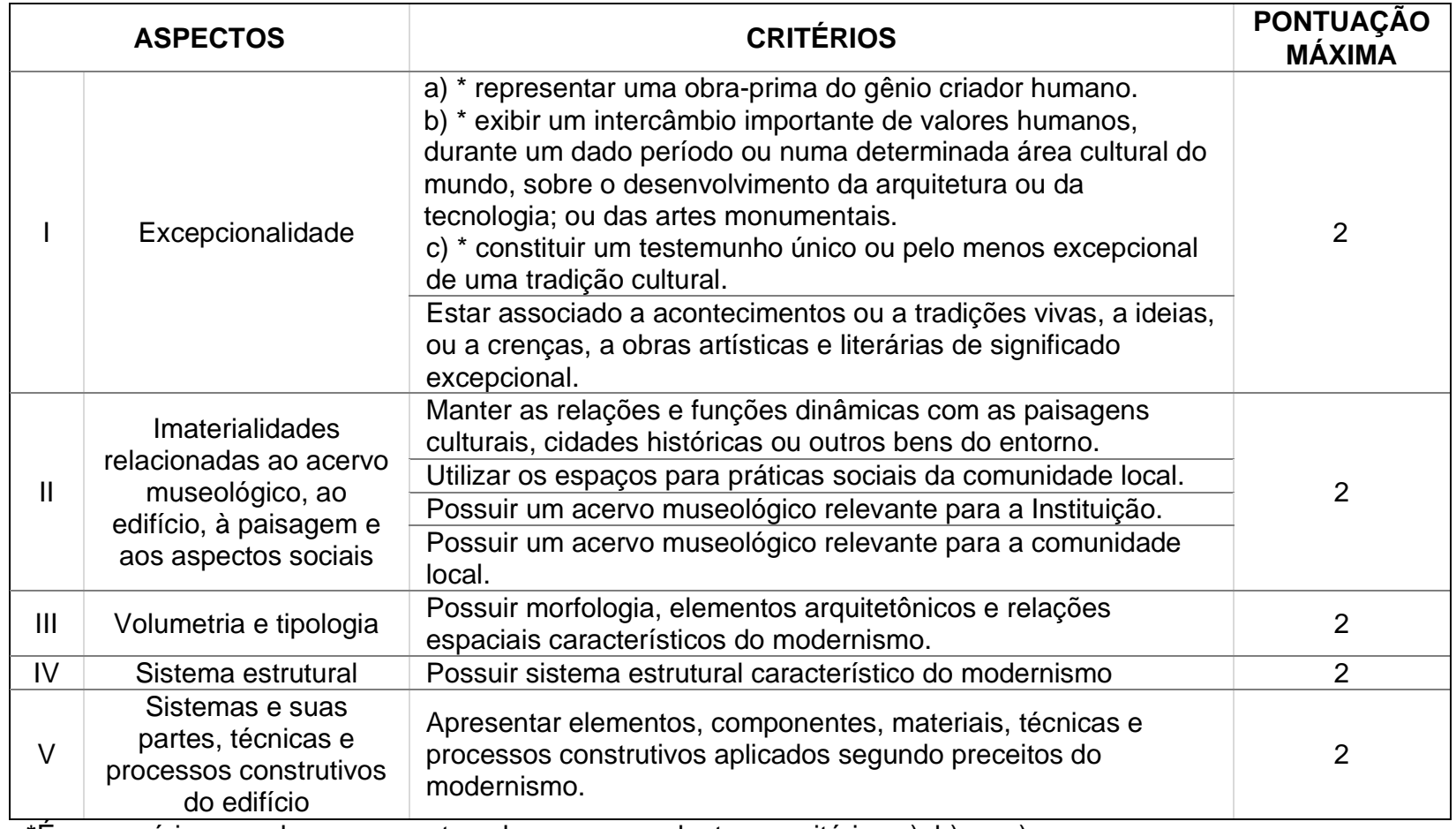

`É necessário que o bem apresente pelo menos um dentre os critérios a), b) ou c).

Fonte: Autores (2019), baseado em Riegl (2014), Lira (2009) e UNESCO (2018).

O número que irá definir o IVC do bem em análise é dado pela soma da pontuação atribuída aos 5 grupos de aspectos, em conformidade com o atendimento aos critérios relacionados. Esse número pode variar de 0 a 10, sendo 0 (zero) caso não atenda nenhum dos critérios adotados e 10 (dez) caso atenda satisfatoriamente todos eles. Quando o valor determinado para o IVC for igual a 0 , isso quer dizer que o edifício em questão não atende aos quesitos mínimos considerados para valores culturais necessários para enquadramento como edifício de interesse de preservação e em situação de vulnerabilidade, no momento da análise.

\section{5 Índice de Conservação (ICO)}

O Índice de Conservação - ICO indica o quão vulnerável se encontra o edifício a partir de seu estado 
de conservação. O ICO foi desdobrado em duas métricas: o Índice de Conservação Absoluto (ICOabs) e o Índice de Conservação Relativo (ICOrel).

O ICOabs é resultante da relação entre o IVC e os fatores A, B, C, D, E, F e G analisados. Quanto menor o valor resultante, mais vulnerável se encontra o edifício. Quanto maior o valor, menor a vulnerabilidade. O ICOrel permite que seja analisado, em porcentagem, o quão vulnerável se encontra o edifício em relação aos valores máximos e mínimos que o museu em questão pode apresentar.

Nas Tabelas 1 e 2 são simuladas as situações com IVC máximo e mínimo, assim como os sete fatores

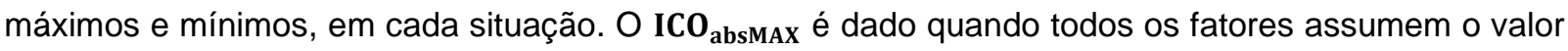

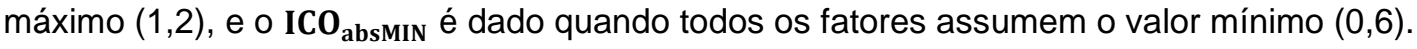

Tabela 1: Simulação de valores com IVC máximo

\begin{tabular}{cccc}
\hline IVC máximo & $($ AxBxCxDxExFxG) máximo de 1,2 para cada fator & ICO $_{\text {absMAX }}$ & ICOrel \\
\hline 10 & 3,58 & 35,8 & $100 \%$ \\
\hline IVC máximo & $($ AxBxCxDxExFxG) mínimo de 0,6 para cada fator & ICO $_{\text {absMIN }}$ & ICOrel \\
\hline 10 & 0,027 & 0,27 & $0,78 \%$ \\
\hline & Fonte: Autores $(2019)$ & &
\end{tabular}

Tabela 2: Simulação de valores com IVC mínimo

\begin{tabular}{ccccc}
\hline IVC mínimo & (AxBxCxDxExFxG) máximo de 1,2 para cada fator & ICO $_{\text {absMAx }}$ & ICOrel \\
\hline 1 & 3,58 & 3,58 & $100 \%$ \\
\hline IVC mínimo & $($ AxBxCxDxExFxG) mínimo de 0,6 para cada fator & ICO $_{\text {absMAx }}$ & ICOrel \\
\hline 1 & 0,027 & 0,027 & $0,78 \%$ \\
\hline & Fonte: Autores $(2019)$ & &
\end{tabular}

O ICOrel é dado em valor percentual e representa a vulnerabilidade segundo os fatores que o afetam. Com a obtenção do ICOrel em porcentagem, é possível comparar os valores encontrados com os valores mínimos e máximos de cada edifício e analisar o quão vulnerável relativamente ele se encontra. Dessa maneira, O ICOrel é dado pela Equação 3.

ICOrel $=\frac{100 \times \mathrm{ICO}_{\mathrm{abs}}}{\mathrm{ICO}_{\mathrm{absMAX}}}$

Onde:

ICOrel = Índice de Conservação Relativo (\%)

$\mathbf{I C O}_{\mathrm{abs}}=$ Índice de Conservação Absoluto

$\mathbf{I C O}_{\text {absMAX }}=$ Índice de Conservação Absoluto Máximo

A Figura 1 representa graficamente o Indicador de Vulnerabilidade (IVU), por meio de suas métricas IVC, ICOabs e o ICOrel, onde cada conjunto de pontos ilustra como ocorre a variação de $0,78 \%$ a $100 \%$ dos valores correspondentes ao ICOrel, para cada IVC (que varia de 1 a 10).

Figura 1: Representação gráfica do Indicador de Vulnerabilidade (IVU)

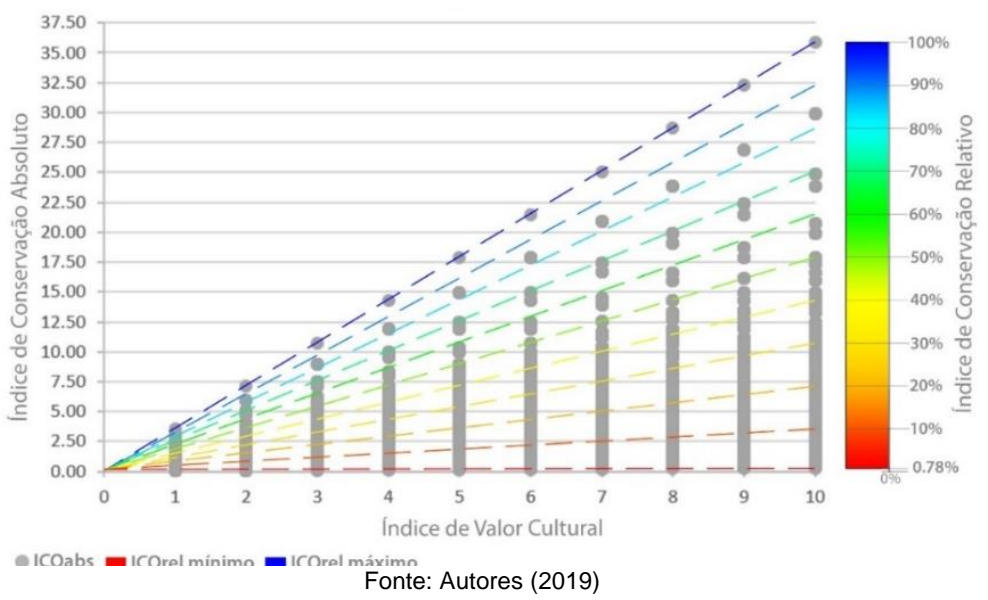


Para o desenvolvimento da representação gráfica do Indicador de Vulnerabilidade (Figura 1) foi criada uma base de dados com 163.840 dados $\left(10 \times 4^{7}\right)$ resultante da expressão matemática do modelo proposto, que combina todas as possibilidades entre os valores das variáveis IVC, A, B, C, D, E, F e G. A representação gráfica do Indicador de Vulnerabilidade (IVU) é a síntese do método proposto. Nas linhas diagonais localizam-se os pontos de igual vulnerabilidade, independentemente da dimensão do valor cultural do bem. Quando registrados no gráfico os resultados de um conjunto de avaliações, o posicionamento sobre as linhas diagonais permite avaliar comparativamente a vulnerabilidade dos diversos tipos de bem cultural entre si, favorecendo hierarquicamente a tomada de decisão no processo de gestão.

\section{Aplicação do Método IVU no Museu Nacional - MuN do Conjunto Cultural da República}

Neste item é apresentado o resultado da aplicação do Método IVU - Indicador de Vulnerabilidade no Museu Nacional do Conjunto Cultural da República, em Brasília-DF.

A aplicação do Método IVU no Museu Nacional mostra, inclusive, as ferramentas desenvolvidas (Quadros de 1 a 9) que foram utilizadas para a determinação de cada um dos fatores envolvidos e o cálculo do IVU. Para cada fator é apresentado um quadro com os critérios que devem ser observados para a avaliação das evidências encontradas no edifício e o valor numérico correspondente. $O$ conteúdo dos quadros pode ser alterado (ampliado ou reduzido) conforme as necessidades e caracterização do edifício que esteja sendo analisado.

\subsection{O Museu Nacional - MuN}

Lucio Costa já havia previsto um museu no Plano Piloto de Brasília. Naquele momento, o museu previsto não foi construído, assim como também não foi construído o museu proposto em 1970, no então Conjunto Cultural de Brasília. Em 1999, Oscar Niemeyer propôs um novo projeto que compunha - Conjunto Cultural no Setor Cultural Norte (Centro Musical e Cinemas) e o Setor Cultural Sul (Biblioteca e Museu). Para unir os dois setores, foi proposta uma passagem subterrânea com estacionamento e lojas.

O projeto inicial, que contava com metade do diâmetro que foi de fato construído, e com janelas circulares para iluminação, foi alterado para que se adequasse melhor à escala monumental da Esplanada dos Ministérios. A decisão de duplicar seu tamanho foi feita no ano de 2002 e sua estrutura e forma arquitetural se fundem na solução. Apenas em 2006 o Museu Nacional foi inaugurado, no 99o aniversário de seu arquiteto, com a exposição de fotografias e desenhos de Niemeyer. A exposição foi intitulada "Niemeyer por Niemeyer".

O MuN tem como missão "elevar e revelar ao maior número de pessoas possível, a cultura visual contemporânea, com vistas também no seu incentivo, difusão e seu reconhecimento pleno como um bem cultural universal, que deve ser preservado e democratizado. Pautado pela liberdade de expressão, este museu visa ainda, abrigar manifestações culturais diversas, que venham contribuir para a pesquisa e a experimentação das diversas linguagens artísticas e culturais, com vistas no seu fomento, difusão e facilitação ao seu acesso, por meios formativos e informativos ágeis, globais e sócio-educativos"1.

Possui um acervo próprio composto principalmente por obras de artes visuais modernas e contemporâneas, principalmente de artistas brasileiros. Seu acervo é de aproximadamente 1000 peças. O museu apresenta menor atividade no período diurno, por conta do espaço árido resultante da ausência da vegetação e praça seca em concreto criada por Niemeyer, que também provoca

\footnotetext{
${ }^{1}$ Disponível em: <http://www.cultura.df.gov.br/museu-nacional/>. Acesso em: 05 de fevereiro de 2019.
} 
ofuscamento a depender da hora do dia. Mas no período noturno, o espaço é conhecido pelos eventos culturais, shows e festas. Durante o dia também são feitas outras ações artísticas e atos políticos.

Quando o Museu de Arte de Brasília - MAB foi interditado, em 2007, parte de seu acervo foi direcionado ao $\mathrm{MuN}$, aumentando o número de peças sob a guarda da instituição e agregando obras importantes ao acervo, mesmo que de maneira não permanente. Esse acervo, de grande importância em âmbito nacional, conta com aproximadamente 1300 peças que são abrigadas em sala separada do acervo próprio da instituição, próximo à administração do Museu, também no piso térreo.

A Figura 2 apresenta a arquitetura do MuN acompanhada da Ficha Técnica, sua área externa e interna. Na Figura 3 é mostrado um corte técnico da arquitetura onde são representados os níveis dos pavimentos.

Figura 2: Imagens do MuN. a) Área externa. b) Arena interna.

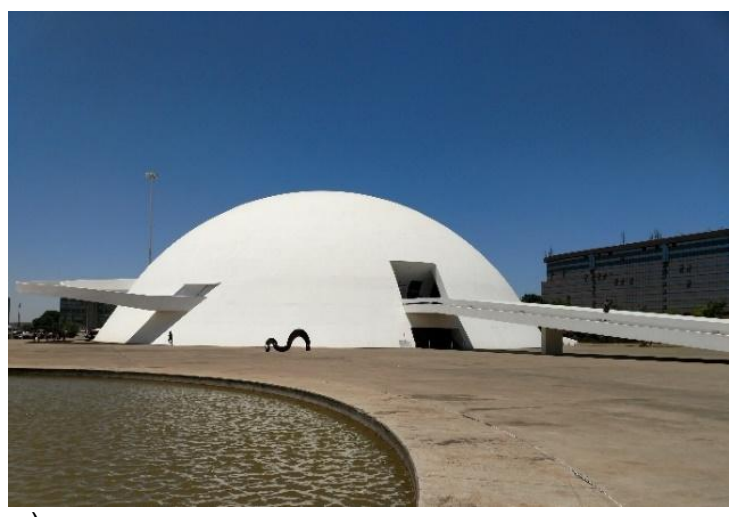

a)

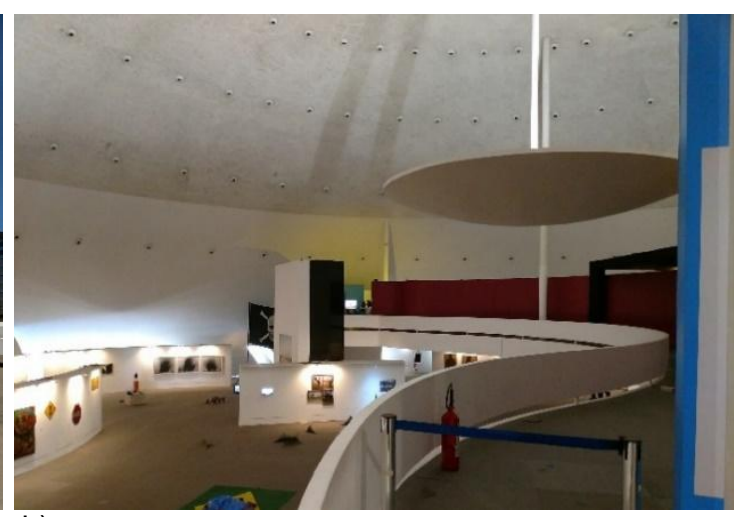

b)

Fonte: Autores (2019)

\begin{tabular}{|c|c|}
\hline \multicolumn{2}{|c|}{ FICHA TÉCNICA MuN } \\
\hline Nome do edifício & Museu Nacional do Conjunto Cultural da República (MuN) \\
\hline Cidade / Estado & Brasília / DF \\
\hline Zona bioclimática (ABNT NBR 15220-3) & Zona 4 \\
\hline Endereço & $\begin{array}{l}\text { Setor Cultural Sul, lote 2, próximo à Rodoviária do Plano Piloto } \\
\text { - Zona } 0 \text { - Brasília, DF, CEP: } 70070-150\end{array}$ \\
\hline Arquiteto & Oscar Niemeyer \\
\hline Engenheiro & José Carlos Sussekind \\
\hline Data de inauguração & 15 de dezembro de 2006 \\
\hline Edifício $x$ função & Edifício construído para ser museu \\
\hline Código IPHAN & $\begin{array}{l}\text { DF5300108BICA0000 (Conjunto Cultural da República) - } \\
\text { Número Processo "T" } 1550\end{array}$ \\
\hline Área total construída & $13.653 \mathrm{~m}^{2}$ \\
\hline Número de edificações & 1 (uma) \\
\hline Número de pavimentos & Auditório semi-enterrado, térreo, $1^{\circ}$ pavimento e mezanino \\
\hline Principal sistema estrutural & Concreto armado (INOJOSA et al., 2011) \\
\hline Sistema de vedação de fachada & Concreto armado \\
\hline Sistema de esquadrias & $\begin{array}{l}\text { O edifício apresenta portas principais metálicas, algumas } \\
\text { confeccionadas sob medida por conta das formas do prédio. O } \\
\text { MuN não possui janelas para o exterior. }\end{array}$ \\
\hline Cobertura & $\begin{array}{l}\text { A cobertura é constituída pela cúpula em concreto armado, } \\
\text { com impermeabilização e pintura na cor branca. }\end{array}$ \\
\hline
\end{tabular}


Figura 3: Corte longitudinal do MuN

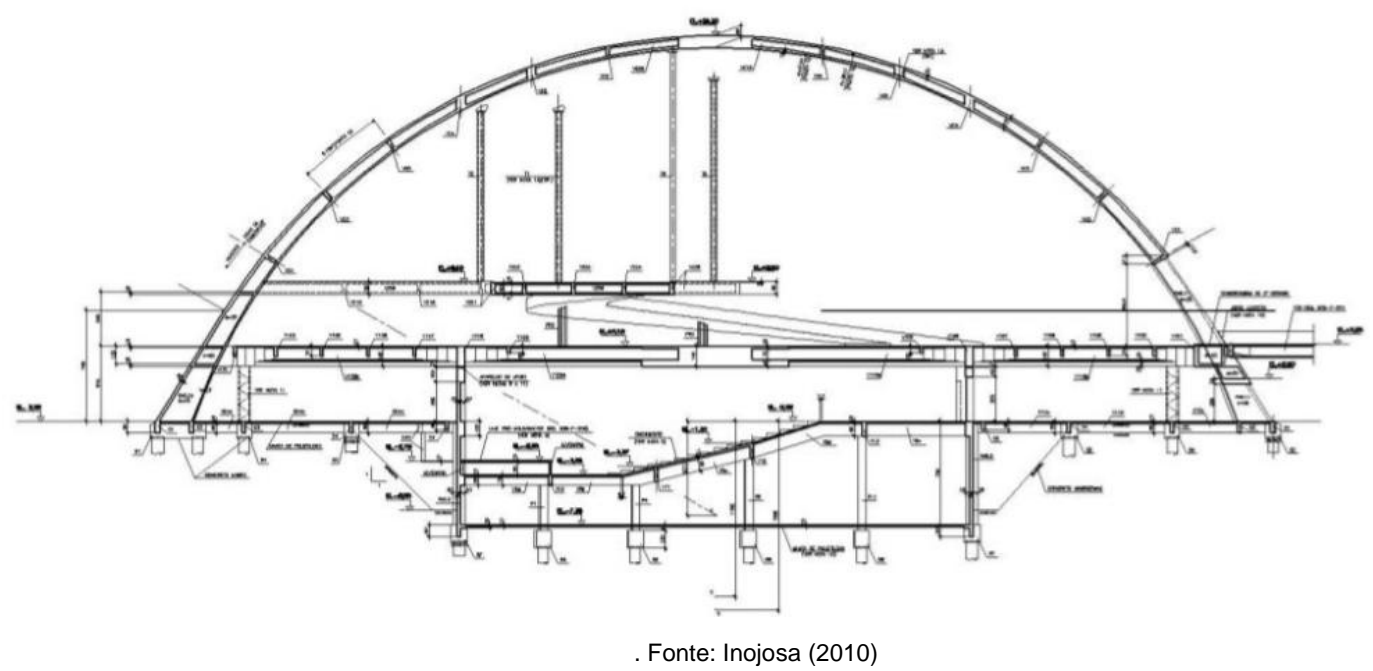

O edifício apresenta um pavimento semienterrado, onde está localizado o maior auditório, para 700 lugares. No andar térreo, com entrada por baixo da rampa principal, estão o foyer, também utilizado para exposições; o auditório menor para 80 lugares; e, do lado oposto ao auditório, existe um grande corredor e salas que também são utilizados eventualmente para exposições. Do lado oposto da entrada principal, ainda no térreo, está localizada a entrada de serviço, por onde também são acessadas as áreas administrativas e as áreas restritas, como as reservas técnicas. Essa entrada, de maior dimensão, possibilita o egresso de peças de diversos tamanhos e formas, dando acesso também ao elevador de carga, que facilita a transferência de objetos de grande dimensão para as áreas expositivas.

O museu possui duas rampas externas executadas em concreto armado, com acabamento em pintura de cor clara. Uma delas é completamente em vão livre e se liga à cúpula, com apoios apenas nas extremidades.

A cúpula tem 80 metros de diâmetro e 25 metros de altura. Na Figura 3 é possível ver, em corte, a distribuição dos principais espaços do MuN. A rampa principal dá acesso ao primeiro pavimento, onde está situada a galeria principal do museu. A cúpula permite o grande vão livre. Para que sejam viabilizadas as exposições são utilizadas paredes móveis em MDF. A base da cúpula (parte interior) recebeu revestimento com placas de gesso pintadas com tinta branca. A parte superior da cúpula recebeu revestimento acústico. A parte exterior da cúpula foi impermeabilizada e pintada na cor branca.

Uma rampa com formas sinuosas liga o térreo ao mezanino, que é uma estrutura de formas orgânicas. Ele é suspenso por tirantes na laje da cúpula, permitindo que o vão abaixo da laje do mezanino fique livre, assim como o próprio mezanino. No nível do mezanino, posiciona-se um grande lustre fixado por tirantes; o lustre é côncavo em relação ao teto da cúpula, proporcionando a iluminação indireta de todo o espaço por reflexão. Existe também um sistema de iluminação no piso. Muitas vezes, são utilizados recortes de carpete para cobrir parte da iluminação do piso, já que todas elas são acionadas simultaneamente.

As salas de reserva técnica possuem piso em granitina clara, paredes com pintura branca e teto em forro de gesso. As salas de reserva técnica possuem medição e controle de temperatura e umidade, porém o sistema não é separado do sistema geral do prédio. Foi feito estudo em 2011, conforme arquivos disponibilizados pelo MuN, que constataram ser $22,5^{\circ}$ a temperatura ideal para conforto ambiental dos espaços. Essa medida foi feita pensando em uma exposição específica proveniente do 
Rio de Janeiro, onde as condições deveriam estar próximas ao de local de origem desse acervo. Apesar disso, os parâmetros foram adotados de maneira contínua pela instituição, não levando em consideração as fragilidades e necessidades de seu acervo próprio.

\subsection{Obtenção do Índice de Valor Cultural (IVC) do MuN}

O Quadro 2 apresenta as evidências encontradas no edifício que permitiram determinar o valor numérico (destacado em cinza) de cada aspecto analisado, baseado nos critérios estabelecidos no Quadro 1.

O Museu Nacional do Conjunto Cultural da República atende satisfatoriamente a todos os aspectos e seus critérios para a avaliação do valor cultural em museus modernistas. Sua valoração resultou em uma avaliação onde a somatória é IVC=10.

Quadro 2: Resultado dos valores atribuídos ao MuN para a valoração de seu IVC

\begin{tabular}{|c|c|c|c|}
\hline \multicolumn{2}{|r|}{ ASPECTOS } & \multirow[b]{2}{*}{$\begin{array}{l}\text { EVIDÊNCIAS } \\
\text { O edifício foi projetado por Oscar Niemeyer, importante arquiteto } \\
\text { modernista Brasileiro } \\
\text { O edifício foi considerado importante obra arquitetônica e de } \\
\text { engenharia moderna (por seus vãos livres e grandes rampas } \\
\text { curvas em balanço), tendo sido inscrita em livro do tombo pelo } \\
\text { IPHAN, pelo seu significado excepcional. }\end{array}$} & \multirow{3}{*}{$\begin{array}{l}\text { AVALIAÇÃO } \\
2\end{array}$} \\
\hline \multirow[t]{2}{*}{1} & \multirow[t]{2}{*}{ Excepcionalidade } & & \\
\hline & & $\begin{array}{l}\text { A obra mantém sua relação com a paisagem e entorno, dialogando } \\
\text { inclusive com uma série de edifícios projetados pelo mesmo } \\
\text { arquiteto. }\end{array}$ & \\
\hline \multirow{4}{*}{ II } & \multirow{4}{*}{$\begin{array}{l}\text { Imaterialidades } \\
\text { relacionadas ao } \\
\text { acervo } \\
\text { museológico, ao } \\
\text { edifício, à paisagem } \\
\text { e aos aspectos } \\
\text { sociais }\end{array}$} & $\begin{array}{l}\text { Manifestações culturais, shows, protestos e outras atividades } \\
\text { públicas ocorrem no interior do museu e em seu entorno imediato } \\
\text { durante todo o ano. }\end{array}$ & \multirow{4}{*}{2} \\
\hline & & $\begin{array}{l}\text { O MuN possui um acervo próprio composto principalmente por } \\
\text { obras de artes visuais modernas e contemporâneas, } \\
\text { principalmente de artistas brasileiros. Seu acervo é de } \\
\text { aproximadamente } 1000 \text { peças. }\end{array}$ & \\
\hline & & $\begin{array}{l}\text { Além de seu acervo próprio, o MuN conta com aproximadamente } \\
1300 \text { peças provenientes do Museu de Arte de Brasília - MAB, } \\
\text { muito relevante para a cidade e para o país. }\end{array}$ & \\
\hline & & $\begin{array}{l}\text { Possui elementos característicos modernos e traços conhecidos de } \\
\text { seu arquiteto, como vãos livres, desenho orgânico proporcionado } \\
\text { pela plasticidade do concreto armado, e a cor branca em seu } \\
\text { exterior, que compõe com outros edifícios monumentais da cidade. }\end{array}$ & \\
\hline III & $\begin{array}{l}\text { Volumetria e } \\
\text { tipologia }\end{array}$ & Concreto armado definindo estrutura e arquitetura. & 2 \\
\hline IV & Sistema estrutural & $\begin{array}{l}\text { Uso do concreto armado em formas não tradicionais, sistema } \\
\text { estrutural proporcionando grandes vãos livres e grandes rampas } \\
\text { curvas em balanço. }\end{array}$ & 2 \\
\hline V & $\begin{array}{l}\text { Sistemas e suas } \\
\text { partes, técnicas e } \\
\text { processos } \\
\text { construtivos do } \\
\text { edifício }\end{array}$ & $\begin{array}{l}\text { O edifício foi considerado importante obra arquitetônica e de } \\
\text { engenharia, por seus vãos livres e grandes rampas curvas em } \\
\text { balanço. }\end{array}$ & 2 \\
\hline
\end{tabular}

\subsection{Obtenção dos Fatores A, B, C, D, E, F, G no MuN}

Os Quadros enumerados de 3 a 9 apresentam cada um dos fatores que afetam os museus e relacionam os critérios adotados para a avaliação das evidências encontradas, permitindo assim ponderar um valor numérico. $O$ destaque em cinza marca o valor numérico resultante da avaliação de cada fator, a partir das evidências encontradas no edifício de valor cultural e seu acervo museológico. 
Quadro 3: Valoração do Fator A - Nível de qualidade dos sistemas e suas partes: elementos, componentes e materiais construtivos do MuN

\begin{tabular}{|c|c|c|c|c|}
\hline FATOR & DESCRIÇÃO DO FATOR & EVIDÊNCIAS & CRITÉRIOS & AVALIAÇÂO \\
\hline \multirow{4}{*}{$\begin{array}{c}\text { A } \\
\text { Nível de } \\
\text { qualidade } \\
\text { dos sistemas } \\
\text { e suas } \\
\text { partes: } \\
\text { elementos, } \\
\text { componentes } \\
\text { e materiais } \\
\text { construtivos }\end{array}$} & \multirow{4}{*}{$\begin{array}{l}\text { Evidências encontradas } \\
\text { indicam que o nível da } \\
\text { qualidade dos projetos } \\
\text { complementares e a } \\
\text { materialização e } \\
\text { especificação dos seus } \\
\text { respectivos subsistemas } \\
\text { e partes afetam a vida } \\
\text { útil e os valores da } \\
\text { edificação e do acervo } \\
\text { museológico. }\end{array}$} & \multirow{4}{*}{$\begin{array}{l}\text { - Fissuras. } \\
\text { - Sujidades. } \\
\text { - Manchas de } \\
\text { umidade. }\end{array}$} & $\begin{array}{l}0 \text { a } 10 \% \text { das evidências encontradas } \\
\text { afetam os valores e a vida útil do } \\
\text { edifício e seu acervo museológico. }\end{array}$ & 1,2 \\
\hline & & & $\begin{array}{c}>10 \% \text { a } 30 \% \text { das evidências } \\
\text { encontradas afetam os valores e a } \\
\text { vida útil do edifício e seu acervo } \\
\text { museológico. }\end{array}$ & 1 \\
\hline & & & $\begin{array}{c}>30 \% \text { a } 50 \% \text { das evidências } \\
\text { encontradas afetam os valores e a } \\
\text { vida útil do edifício e seu acervo } \\
\text { museológico. }\end{array}$ & 0,8 \\
\hline & & & $\begin{array}{c}\text { Mais de } 50 \% \text { das evidências } \\
\text { encontradas afetam os valores e a } \\
\text { vida útil do edifício e seu acervo } \\
\text { museológico. }\end{array}$ & 0,6 \\
\hline
\end{tabular}

Quadro 4: Valoração do Fator B - Nível de qualidade do projeto arquitetônico do MuN

\begin{tabular}{|c|c|c|c|c|}
\hline FATOR & $\begin{array}{c}\text { DESCRIÇÂO } \\
\text { DO FATOR }\end{array}$ & EVIDÊNCIAS & CRITÉRIOS & AVALIAÇÂO \\
\hline \multirow[t]{4}{*}{$\begin{array}{c}\text { B } \\
\text { Nível de } \\
\text { qualidade do } \\
\text { projeto } \\
\text { arquitetônico }\end{array}$} & \multirow{4}{*}{$\begin{array}{l}\text { Evidências } \\
\text { encontradas } \\
\text { indicam que o } \\
\text { nível da } \\
\text { qualidade de } \\
\text { projeto afeta a } \\
\text { vida útil e os } \\
\text { valores da } \\
\text { edificação e } \\
\text { do acervo } \\
\text { museológico. }\end{array}$} & \multirow{4}{*}{ 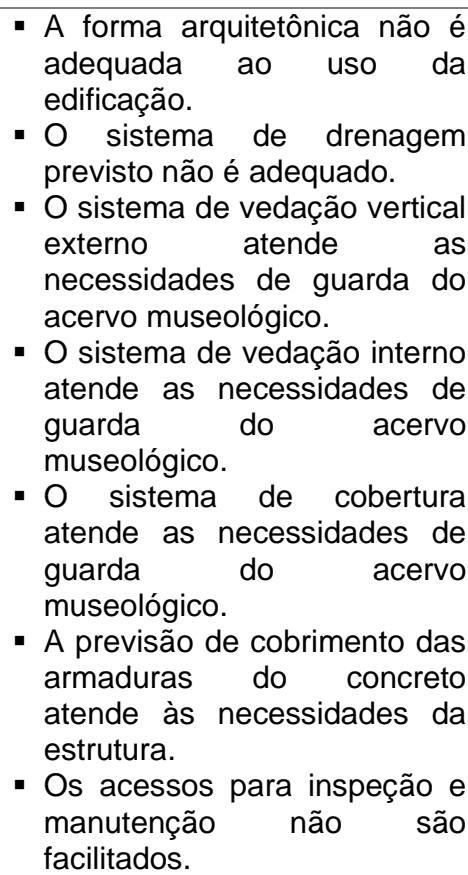 } & $\begin{array}{c}0 \text { a } 10 \% \text { das evidências } \\
\text { encontradas afetam os } \\
\text { valores e a vida útil do } \\
\text { edifício e seu acervo } \\
\text { museológico. }\end{array}$ & 1,2 \\
\hline & & & $\begin{array}{c}>10 \% \text { a } 30 \% \text { das } \\
\text { evidências encontradas } \\
\text { afetam os valores e a vida } \\
\text { útil do edifício e seu acervo } \\
\text { museológico. }\end{array}$ & 1 \\
\hline & & & $\begin{array}{c}>30 \% \text { a } 50 \% \text { das } \\
\text { evidências encontradas } \\
\text { afetam os valores e a vida } \\
\text { útil do edifício e seu acervo } \\
\text { museológico. }\end{array}$ & 0,8 \\
\hline & & & $\begin{array}{c}\text { Mais de } 50 \% \text { das } \\
\text { evidências encontradas } \\
\text { afetam os valores e a vida } \\
\text { útil do edifício e seu acervo } \\
\text { museológico. }\end{array}$ & 0,6 \\
\hline
\end{tabular}

Quadro 5: Valoração do Fator C - Nível de qualidade de execução da obra do MuN

\begin{tabular}{|c|c|c|c|c|}
\hline FATOR & $\begin{array}{c}\text { DESCRICCÃO } \\
\text { DO FATOR }\end{array}$ & EVIDÊNCIAS & CRITÉRIOS & AVALIAÇÂO \\
\hline \multirow{4}{*}{$\begin{array}{c}\text { C } \\
\text { Nível de } \\
\text { qualidade de } \\
\text { execução da } \\
\text { obra }\end{array}$} & \multirow{4}{*}{$\begin{array}{l}\text { Evidências } \\
\text { encontradas } \\
\text { indicam que o } \\
\text { nível da } \\
\text { qualidade de } \\
\text { execução da } \\
\text { obra afeta a } \\
\text { vida útil e os } \\
\text { valores da } \\
\text { edificação e } \\
\text { do acervo } \\
\text { museológico. }\end{array}$} & \multirow{4}{*}{$\begin{array}{l}\text { - Defeitos de } \\
\text { nivelamento } \\
\text { das formas. } \\
\text { - Marcas de } \\
\text { fixação das } \\
\text { formas. }\end{array}$} & $\begin{array}{c}0 \text { a } 10 \% \text { das evidências encontradas afetam os } \\
\text { valores e a vida útil do edifício e seu acervo } \\
\text { museológico. }\end{array}$ & 1,2 \\
\hline & & & $\begin{array}{c}>10 \% \text { a } 30 \% \text { das evidências encontradas } \\
\text { afetam os valores e a vida útil do edifício e seu } \\
\text { acervo museológico. }\end{array}$ & 1 \\
\hline & & & $\begin{array}{c}>30 \% \text { a } 50 \% \text { das evidências encontradas } \\
\text { afetam os valores e a vida útil do edifício e seu } \\
\text { acervo museológico. }\end{array}$ & 0,8 \\
\hline & & & $\begin{array}{l}\text { Mais de } 50 \% \text { das evidências encontradas } \\
\text { afetam os valores e a vida útil do edifício e seu } \\
\text { acervo museológico. }\end{array}$ & 0,6 \\
\hline
\end{tabular}


Quadro 6: Valoração do Fator D - Características do ambiente interno do MuN

\begin{tabular}{|c|c|c|c|c|}
\hline FATOR & $\begin{array}{c}\text { DESCRIÇÃO DO } \\
\text { FATOR }\end{array}$ & EVIDÊNCIAS & CRITÉRIOS & AVALIAÇÂO \\
\hline \multirow[t]{4}{*}{$\begin{array}{c}\text { D } \\
\text { Características } \\
\text { do ambiente } \\
\text { interno }\end{array}$} & \multirow{4}{*}{$\begin{array}{l}\text { Evidências } \\
\text { encontradas } \\
\text { indicam que a } \\
\text { qualidade do } \\
\text { ambiente } \\
\text { interno do } \\
\text { edifício afeta a } \\
\text { conservação de } \\
\text { seu acervo } \\
\text { museológico. }\end{array}$} & \multirow{4}{*}{$\begin{array}{l}\text { - Medidores de temperatura } \\
\text { atendem às necessidades do } \\
\text { acervo. } \\
\text { - Medidores de umidade atendem } \\
\text { às necessidades do acervo. } \\
\text { - Controle de temperatura atende } \\
\text { às necessidades do acervo } \\
\text { - Controle de umidade atende às } \\
\text { necessidades do acervo. } \\
\text { - Temperatura no ambiente não } \\
\text { atende às necessidades do } \\
\text { acervo. } \\
\text { - Umidade no ambiente não } \\
\text { atende às necessidades do } \\
\text { acervo lua } \\
\text { - Incidência de luz atende as } \\
\text { necessidades do acervo. } \\
\text { - Não apresenta infestações por } \\
\text { agentes biológicos (ex: insetos } \\
\text { xilófagos, traças e baratas; } \\
\text { fungos e bactérias; roedores). } \\
\text { - Atende às exigências de } \\
\text { prevenção a incêndio. } \\
\text { - Não atende às exigências de } \\
\text { combate a incêndio. }\end{array}$} & $\begin{array}{c}0 \text { a } 10 \% \text { das evidências } \\
\text { encontradas afetam as } \\
\text { características do } \\
\text { ambiente interno e o } \\
\text { acervo do museu. }\end{array}$ & 1,2 \\
\hline & & & $\begin{array}{c}>10 \% \text { a } 30 \% \text { das } \\
\text { evidências encontradas } \\
\text { afetam as } \\
\text { características do } \\
\text { ambiente interno e o } \\
\text { acervo do museu. }\end{array}$ & 1 \\
\hline & & & $\begin{array}{c}>30 \% \text { a } 50 \% \text { das } \\
\text { evidências encontradas } \\
\text { afetam as } \\
\text { características do } \\
\text { ambiente interno e o } \\
\text { acervo do museu. }\end{array}$ & 0,8 \\
\hline & & & $\begin{array}{c}\text { Mais de } 50 \% \text { das } \\
\text { evidências encontradas } \\
\text { afetam as } \\
\text { características do } \\
\text { ambiente interno e o } \\
\text { acervo do museu. }\end{array}$ & 0,6 \\
\hline
\end{tabular}
Fonte: Autores (2019)

Quadro 7: Valoração do Fator E - Características do ambiente externo do MuN

\begin{tabular}{|c|c|c|c|c|}
\hline FATOR & $\begin{array}{c}\text { DESCRIÇÃO } \\
\text { DO FATOR }\end{array}$ & EVIDÊNCIAS & CRITÉRIOS & AVALIAÇÂO \\
\hline \multirow[t]{4}{*}{$\begin{array}{c}E \\
\text { Características } \\
\text { do ambiente } \\
\text { externo }\end{array}$} & \multirow{4}{*}{$\begin{array}{l}\text { Evidências } \\
\text { encontradas } \\
\text { indicam que } \\
\text { as } \\
\text { características } \\
\text { do ambiente } \\
\text { externo } \\
\text { afetam a vida } \\
\text { útil e os } \\
\text { valores da } \\
\text { edificação e } \\
\text { do acervo } \\
\text { museológico. }\end{array}$} & \multirow{4}{*}{ 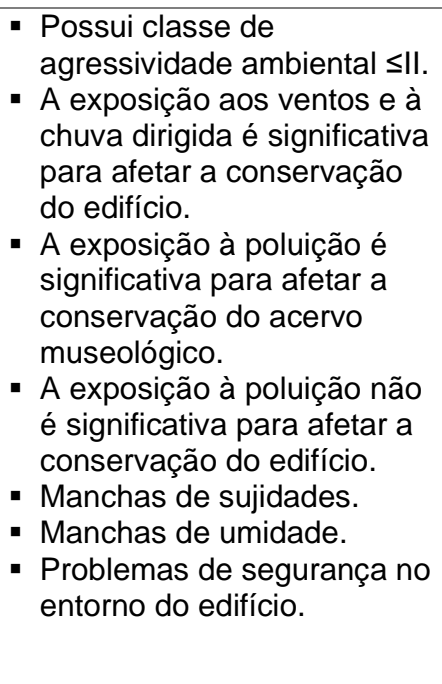 } & $\begin{array}{l}0 \text { a } 10 \% \text { das evidências } \\
\text { encontradas afetam os } \\
\text { valores e a vida útil do edifício } \\
\text { e seu acervo museológico. }\end{array}$ & 1,2 \\
\hline & & & $\begin{array}{l}>10 \% \text { a } 30 \% \text { das evidências } \\
\text { encontradas afetam os } \\
\text { valores e a vida útil do edifício } \\
\text { e seu acervo museológico. }\end{array}$ & 1 \\
\hline & & & $\begin{array}{l}>30 \% \text { a } 50 \% \text { das evidências } \\
\text { encontradas afetam os } \\
\text { valores e a vida útil do edifício } \\
\text { e seu acervo museológico. }\end{array}$ & 0,8 \\
\hline & & & $\begin{array}{l}\text { Mais de } 50 \% \text { das evidências } \\
\text { encontradas afetam os } \\
\text { valores e a vida útil do edifício } \\
\text { e seu acervo museológico. }\end{array}$ & 0,6 \\
\hline
\end{tabular}


Quadro 8: Valoração do Fator F - Condições de uso do MuN

\begin{tabular}{|c|c|c|c|c|}
\hline FATOR & $\begin{array}{c}\text { DESCRIÇÃO DO } \\
\text { FATOR }\end{array}$ & EVIDÊNCIAS & CRITÉRIOS & AVALIAÇÂO \\
\hline \multirow[t]{4}{*}{$\begin{array}{c}\mathrm{F} \\
\text { Condições } \\
\text { de uso }\end{array}$} & \multirow{4}{*}{$\begin{array}{l}\text { Evidências } \\
\text { encontradas } \\
\text { indicam que as } \\
\text { condições de uso } \\
\text { afetam a vida útil e } \\
\text { os valores da } \\
\text { edificação e do } \\
\text { acervo } \\
\text { museológico. }\end{array}$} & \multirow[t]{4}{*}{$\begin{array}{l}\text { - Uso regular } \\
\text { do edifício. } \\
\text { - Pichações. }\end{array}$} & $\begin{array}{l}0 \text { a } 10 \% \text { das evidências encontradas } \\
\text { afetam os valores e a vida útil do edifício e } \\
\text { seu acervo museológico. }\end{array}$ & 1,2 \\
\hline & & & $\begin{array}{l}>10 \% \text { a } 30 \% \text { das evidências encontradas } \\
\text { afetam os valores e a vida útil do edifício e } \\
\text { seu acervo museológico. }\end{array}$ & 1 \\
\hline & & & $\begin{array}{l}>30 \% \text { a } 50 \% \text { das evidências encontradas } \\
\text { afetam os valores e a vida útil do edifício e } \\
\text { seu acervo museológico. }\end{array}$ & 0,8 \\
\hline & & & $\begin{array}{l}\text { Mais de } 50 \% \text { das evidências encontradas } \\
\text { afetam os valores e a vida útil do edifício e } \\
\text { seu acervo museológico. }\end{array}$ & 0,6 \\
\hline
\end{tabular}

Quadro 9: Valoração do Fator G - Nível de Manutenção do MuN

\begin{tabular}{|c|c|c|c|}
\hline FATOR & DESCRIÇÃO DO FATOR & CRITÉRIOS & AVALIAÇÂO \\
\hline \multirow{4}{*}{$\begin{array}{c}\mathrm{G} \\
\text { Nível de } \\
\text { manutenção }\end{array}$} & \multirow{4}{*}{$\begin{array}{l}\text { Evidências } \\
\text { encontradas indicam } \\
\text { que o nível de } \\
\text { manutenção afeta a } \\
\text { vida útil e os valores da } \\
\text { edificação e do acervo } \\
\text { museológico. }\end{array}$} & $\begin{array}{l}\text { Manutenções rotineira e preventiva adequadas, } \\
\text { e sem necessidade de manutenção corretiva }\end{array}$ & 1,2 \\
\hline & & $\begin{array}{c}\text { Manutenção planejada: rotineira, preventiva e } \\
\text { corretiva }\end{array}$ & 1 \\
\hline & & Sem manutenção & 0,8 \\
\hline & & Necessidade urgente de manutenção corretiva & 0,6 \\
\hline
\end{tabular}

\subsection{Cálculo do Índice de Conservação do MuN}

A Equação 4 é aplicada para a obtenção do ICOabs, e a Equação 5 resulta no ICOrel . O Quadro 10 apresenta as métricas obtidas na avaliação do MuN.

ICOabs $=$ IVC $\times \mathrm{A} \times \mathrm{B} \times \mathrm{C} \times \mathrm{D} \times \mathrm{E} \times \mathrm{F} \times \mathrm{G}=10 \times 1,2 \times 1,2 \times 1,2 \times 1 \times 1 \times 1 \times 1=17,28$

ICOrel $=\frac{100 \times \mathrm{ICO}_{\mathrm{abs}}}{\mathrm{ICO}_{\text {absMAX }}}=\frac{100 \times 17,28}{35,8}=48,26 \%$

Quadro 10: Quadro resumo dos resultados das métricas no MuN

\begin{tabular}{c|c|c|c|c|c|c|c}
\hline MUSEU & IVC & ICO $_{\text {absMAX }}$ & ICO $_{\text {abs }}$ & ICO $_{\text {absMIN }}$ & ICO $_{\text {relMAX }}$ & ICO $_{\text {rel }}$ & ICO $_{\text {relmIN }}$ \\
\hline MuN & 10 & 35,8 & 17,28 & 0,27 & $100 \%$ & $48,26 \%$ & $0,78 \%$ \\
\hline
\end{tabular}

Para a análise devem ser observados os dados das três últimas colunas do Quadro 10. Para o MuN, o

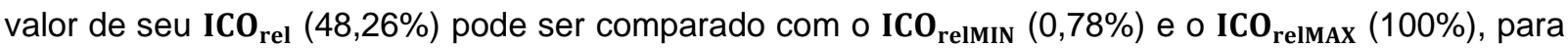
identificar o seu posicionamento em relação ao potencial de vulnerabilidade.

\section{Discussão dos Resultados}

A partir dos resultados obtidos com a aplicação do Método IVU no Museu Nacional do Conjunto Cultural da República é possível compreender melhor o estado de conservação do museu como um todo, tanto de seu edifício quanto de seu acervo, considerando suas questões materiais e imateriais.

Como a intenção é sempre minimizar os riscos aos quais o museu está sujeito, após a aplicação é possível olhar para cada fator, individualmente, a fim de perceber quais evidências detectadas foram determinantes para que o museu perdesse valor. As pontuações numéricas atribuídas e anotadas nas tabelas podem ser hierarquizadas, para que ações a serem tomadas sejam embasadas na avaliação.

Quanto mais próximo o valor do $\mathbf{I C O}_{\text {rel }}$ estiver de seu valor mínimo, mais vulnerável se encontra o edifício, assim como quanto mais próximo ele estiver do ICO $_{\text {relMAX }}$, menos vulnerável esse edifício se encontra em relação aos critérios escolhidos. 
Ao receber uma valoração IVC=10, a posição do $\mathrm{MuN}$ permanece na coluna 10 . Tendo em vista que o ICOrel é igual a $48,26 \%$, ele se encontra muito próximo à diagonal intermediária da ferramenta gráfica construída nesta pesquisa (Figura 4). O posicionamento do MuN na ferramenta gráfica que sintetiza o Indicador de Vulnerabilidade alerta para a necessidade de ações de conservação programadas, no âmbito da manutenção preventiva.

Figura 4: Representação gráfica do Indicador de Vulnerabilidade (IVU) para o MuN comparativamente com outro exemplar aleatório $(\mathrm{Mx})$

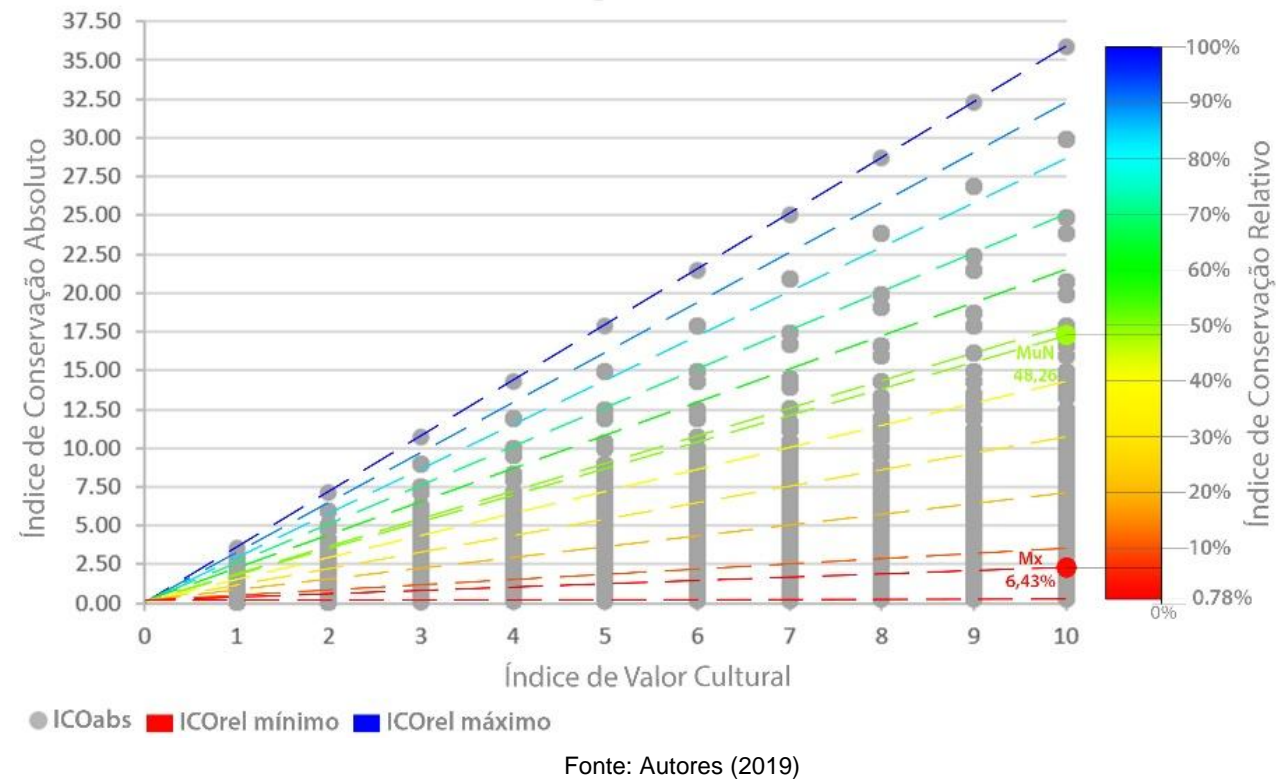

A ferramenta gráfica desenvolvida, não somente permite avaliar individualmente o museu, mas também um conjunto de museus. Na representação gráfica da Figura 4 é possível observar o Museu Nacional do Conjunto Cultural da República (MuN) em relação a outro museu tomado aleatoriamente. Observa-se que apesar dos dois museus apresentarem IVC iguais a 10, isto é, representam os mesmos valores culturais, apresentam situações distintas quanto à sua vulnerabilidade. Enquanto o Museu (Mx), utilizado aqui como referência comparativa, está na faixa vermelha, o MuN se encontra na faixa esverdeada, apresentando menor vulnerabilidade, considerando a análise dos fatores que atuam no edifício. Dessa forma, a aplicabilidade do método se faz clara também dentro de uma amostra com vários exemplares, o que torna viável a gestão de riscos de um conjunto de edifícios, para além de uma unidade isolada.

\section{CONCLUSÃO}

Nesta pesquisa, o modelo teórico do Método Fatorial determinado pela ISO 15686-8: 2008 serviu de referencial para a elaboração do Método IVU - Indicador de Vulnerabilidade que permitiu avaliar, em uma mesma equação, os valores culturais e os fatores que afetam a conservação de edifícios de valor cultural e de acervos museológicos. Os procedimentos metodológicos para a obtenção do Índice de Valor Cultural - IVC baseia-se em um conjunto de critérios pré-estabelecidos, mas que podem ser adaptados para representar a diversidade de museus em edifícios modernistas de valor cultural. Já os critérios adotados para avaliar os sete fatores que afetam a conservação da edificação são flexíveis, podendo ser estabelecidos de acordo com as características e especificidades do edifício.

Dessa maneira, o método proposto se configura como uma ferramenta de gestão, colaborando para o planejamento, a identificação, análise e monitoramento de riscos, podendo ser aplicado tanto em edifícios mais complexos ou aqueles mais convencionais ou de pequeno porte, respeitando sua significância cultural na mesma escala de igualdade, qualquer que seja a sua importância patrimonial. 
A representação gráfica do Método IVU mostrou-se uma ferramenta essencial para a hierarquização da vulnerabilidade dos edifícios analisados, e que se atualizado periodicamente, pode representar um histórico da situação de uma amostra de museus ao longo dos anos. Isso corrobora com as ideias a respeito do processo de retroalimentação das informações de um edifício, como construção constante. A representação gráfica gerada pode auxiliar na visualização dos edifícios vulneráveis em uma amostra específica. Se utilizado com periodicidade, o método pode contribuir para a criação de bases de dados para os edifícios analisados ao longo do tempo, inclusive aprimorando os registros nos casos de edifícios alvos de tombamento pelo Estado.

A metodologia desenvolvida foi pensada para a edifícios modernos de valor cultural que abrigam museus, mas pode ser adaptada para outros tipos e finalidade de edificações. O Índice de Valor Cultural desenvolvido ao longo desta pesquisa mostrou-se suficientemente abrangente, de maneira a englobar aspectos imateriais e materiais, a partir de teorias provenientes desde a primeira metade do séc. $\mathrm{XX}$ até teorias atuais.

Baseado nesta pesquisa, considera-se que um plano museológico implementado nos museus poderia minimizar e/ou eliminar diversos dos problemas encontrados nas instituições analisadas. É importante que esse plano seja desenvolvido por um grupo de profissionais especializados e seja revisitado periodicamente. Quanto mais desenvolvido for o estudo para a identificação das evidências encontradas nos museus, mais fiel à realidade será o resultado do Método IVU. Dessa forma, o sucesso de sua aplicação está ligado ao comprometimento dos especialistas e gestores na análise de sua amostra.

\section{REFERÊNCIAS}

ASSOCIAÇÃO BRASILEIRA DE NORMAS TÉCNICAS. NBR 15575:1 Desempenho de edificações habitacionais - Requisitos Gerais. Rio de Janeiro, 2013.

ASSOCIAÇÃO BRASILEIRA DE NORMAS TÉCNICAS. NBR 5674 Manutenção de edificações Requisitos para o sistema de gestão de manutenção. Rio de Janeiro, 2012.

ASSOCIAÇÃO BRASILEIRA de NORMAS TÉCNICAS. NBR 6118 Projeto de Estruturas de Concreto - Procedimento. Rio de Janeiro, 2014.

BRITISH STANDARD INSTITUTION. BS ISO 15686-8 Buildings and constructed assets - Servicelife planning - Part 8: Reference service life and service-life estimation. International Organization for Standardization: Geneva, Switzerland, 2008.

DRUMOND, M. C. P. Prevenção e conservação no museu. In: Caderno de Diretrizes Museológicas. 2. ed. Brasília: Ministério da Cultura; Instituto do Patrimônio Histórico e Artístico Nacional; Departamento de Museus e Centros Culturais; Belo Horizonte: Secretaria de Estado da Cultura; Superintendência de Museus, 2006.

EMÍDIO, F.; BRITO, J.; GASPAR, P.; SILVA, A. Application of the factor method to the estimation of the service life of natural stone cladding. Construction and Building Materials, 66, 481-493, 2014.

FERREIRA, C. S. F. M. Inércia Higroscópica em Museus Instalados em Edifícios Antigos: Utilização de Técnicas Passivas no Controlo da Humidade Relativa Interior. Tese de Doutorado, Faculdade de Engenharia da Universidade do Porto. Portugal, 2015.

GABRIELE, M. C. F. L. Musealização do Patrimônio Arquitetônico: inclusão social, identidade e cidadania. Museu Vivo da Memória Candanga. Tese (Doutorado). Universidade Lusófona de Humanidades e Tecnologias. Departamento de Museologia, Lisboa, 2012. 
HELENE, P. R. L. Vida Útil das Estruturas de Concreto. IV Congresso Ibero Americano de Patologia das Construções e VI Congresso de Controle da Qualidade CONPAT-97, Porto Alegre, 1997.

ICOM. Definição: Museu. ICON-Portugal, 2015. Disponível em: <http://icomportugal.org/2015/03/19/definicao-museu/>. Acesso: 06 de fevereiro de 2019.

ICOMOS - Austrália. The Burra Charter: The Australia ICOMOS Charter for Places of Cultural Significance, 2013. Disponível em: http://portal.iphan.gov.br/uploads/ckfinder/arquivos/The-BurraCharter-2013-Adopted-31 10 2013.pdf. Acesso: 10 de jun. de 2019.

ICOMOS. Documento de Nara sobre a Autenticidade. Nara: Conferência de Nara, 1994.

INOJOSA, L. S. O Sistema Estrutural na Obra de Oscar Niemeyer. Dissertação de Mestrado. Programa de Pós-Graduação, Faculdade de Arquitetura e Urbanismo, Universidade de Brasília, 2010.

INOJOSA, L. S.; DE GREGORIO, M. H. R.; BUZAR, M. A. R. Aspectos do Projeto Estrutural do Museu Nacional de Brasília. In: CILAMCE - XXXII Iberian Latin-American Congress on Computacional Methods in Engineering, 2011, Ouro Preto-MG. CILAMCE - XXXII Iberian LatinAmerican Congress on Computacional Methods in Engineering, 2011.

JARDIM A., SILVA A., BRITO J. Application of the factor method to the service life prediction of architectural concrete. Canadian Journal of Civil Engineering, Canadian Journal of Civil Engineering, 46 (11), 2019. Disponível em: <https://doi.org/10.1139/cjce-2018-0452>. Acesso em: 12 de fevereiro de 2019.

LIRA, F. B. Patrimônio cultural e autenticidade: montagem de um sistema de indicadores para o monitoramento. 2009. Tese (Doutorado). Programa de Pós-Graduação em Desenvolvimento Urbano, Universidade Federal de Pernambuco, Recife, 2009.

MESQUITA, E.F.T. Engenharia do Patrimônio. Curitiba, Paraná: Íthala, 2019. 184p.

POLITO, G. Gerenciamento de obras: boas práticas para a melhoria da qualidade e da produtividade. São Paulo: Pini, 2015.

RIEGL, A. O culto moderno dos monumentos: a sua essência e a sua origem. Tradução Werner Rothschild Davidsohn, Anat Falbel. São Paulo: Perspectiva, 2014.

SILVA, A.; BRITO, J.; GASPAR, P.L. Methodologies for Service Life Prediction of Buildings - With a Focus on Façade Claddings. Switzerland: Springer, 2016. 432p.

SOUZA, J.; SILVA, A.; BRITO, J.; BAUER, E. Service life prediction of ceramic tiling systems in Brasilia-Brazil using the factor method. Construction and Building Materials, 192, 38-49, 2018.

UNESCO. Gestão do Patrimônio Mundial Cultural (Manual de referência do patrimônio mundial). Brasília: UNESCO Brasil, Iphan, 2016.

UNESCO. Orientações Técnicas para Aplicação da Convenção do Património Mundial. Centro do Património Mundial. Edição em Português, versão 2017. Lisboa, 2018. 